\title{
CURRARINO SYNDROME - A PRE AND POST NATAL DIAGNOSIS CORRELATION: CASE REPORT AND LITERATURE REVIEW
}

Catarina Monteiro Ferreira ${ }^{1}$, Margarida Meira Carvalhoํㅜ, Manuel Gonçalves Henriques ${ }^{1}$, Sara Sardinha Abrantes ${ }^{1}$, Ana Paula Santos ${ }^{1}$, Joaquim Fonseca ${ }^{1}$, Ana Cristina Costa ${ }^{2}$, Antónia Nazaré 3

${ }^{1}$ Obstetrics Department of Hospital Prof. Doutor Fernando Fonseca; ${ }^{2}$ Director of Obstetrics Department of Hospital Prof. Doutor Fernando Fonseca; ${ }^{3}$ Director of Woman Department of Hospital Prof. Doutor Fernando Fonseca

$$
\text { Lisbon, Portugal }
$$

\section{Problem STATEMENT}

$\rightarrow$ Currarino syndrome is a rare autosomal dominant disorder and affected subjects are at-risk of serious complications, leading to significant morbidity and mortality;

$\rightarrow$ This disease is formed by a Currarino triad: sacral anomalies, presacral mass and an anorectal malformation; it exhibits variable expressivity and many heterozygotes are asymptomatic;

$\rightarrow$ Prenatal ultrasonography may identify the presence of a presacral mass, although it is not an accurate or complete investigation for someone at $50 \%$ risk.

\section{METHODS}

$\rightarrow$ We discuss a case report of Currarino Syndrome with an early diagnosis through imagiological study during pregnancy for prenatal diagnostic purposes.

\section{RESULTS}

; 24 years-old Healthy primigravida Suspicion of spina bifida occulta at 21 weeks

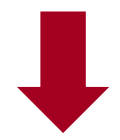

Obstetric ultrasounds and the first fetal magnetic resonance:

$\rightarrow$ Presented first a closed sacrococcygeal dysraphism without meningocele and cerebral alterations like Arnold-Chiari malformations;

$\rightarrow$ At 29 weeks, a small meningocele with lowered medullary cone appeared during second fetal magnetic resonance;
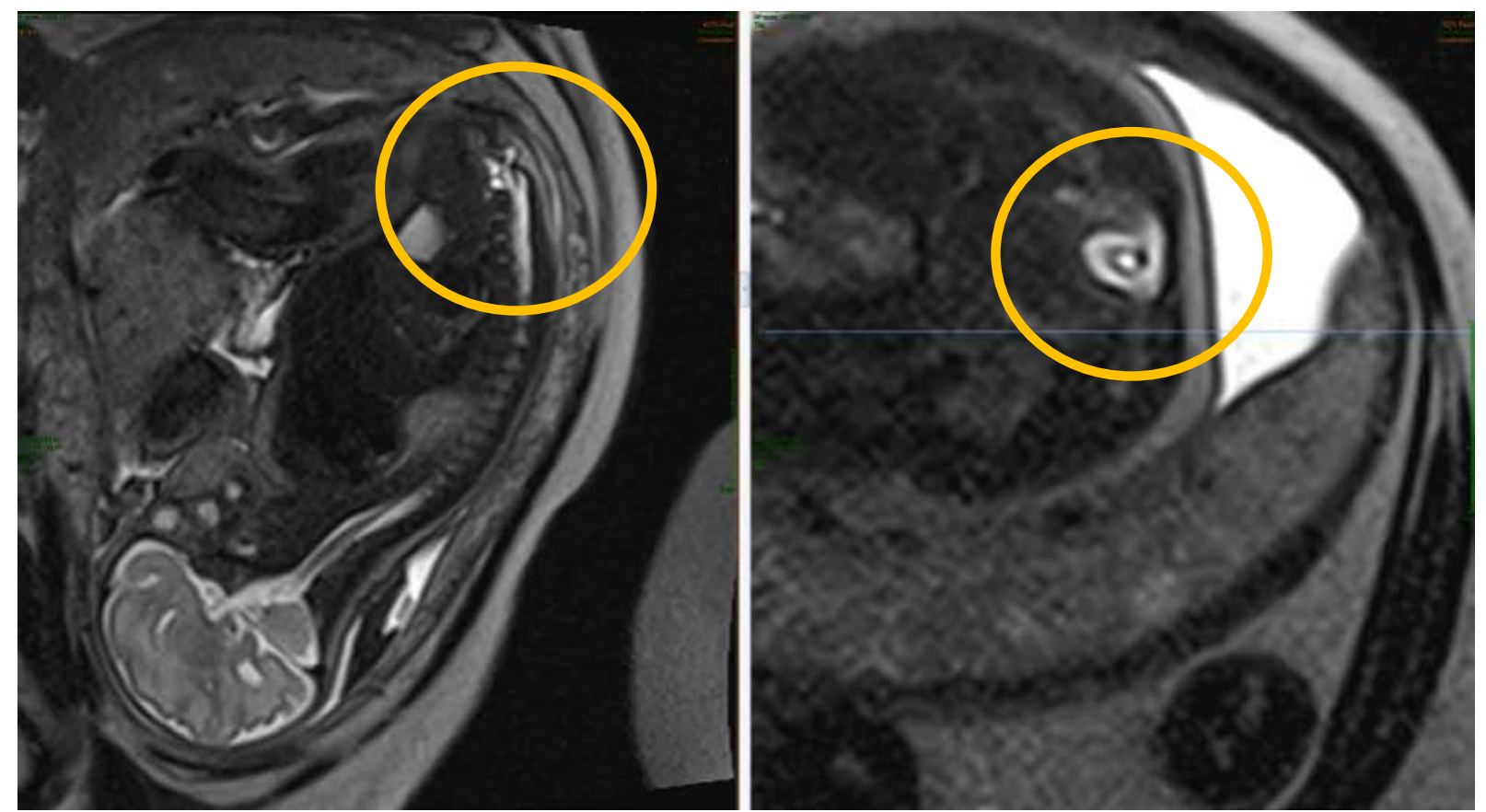

Image 1. Fetal magnetic resonance at 29 weeks.
Term vaginal delivery;

Female newborn, 3315gr, Apgar score 9/9/10

Perianal and endorectal polypoid mass

$\rightarrow$ Magnetic resonance: Partial sacral agenesis + anterior myelomeningocele + rectosacral mass + anchored medulla (cone in L4);

$\rightarrow$ After these results neurosurgical team analysed the fetal resonance and discovered similar neural tube defects in the asymptomatic mother: sacral agenesis and anterior meningocele;

$\rightarrow$ Afterwards, we had an early CURRARINO SYNDROME DIAGNOSIS and performed a neurosurgery to allow the medullar distal release and filum terminal section;

$\rightarrow$ The child has 1 year and a normal physical and psychomotor development, with symmetric leg movement and a normal intestinal transit;

$\rightarrow$ She will be monitored by a multidisciplinary team to evaluate her evolution, specially locomotion and sphincter control.

\section{CONCLUSION}

$\rightarrow$ Despite the difficulty of doing a prenatal diagnosis of this syndrome, whenever we detect a presacral mass during the obstetric ultrasounds, we advise the inclusion of Currarino syndrome in the differential diagnosis of neural tube defects;

$\rightarrow$ We should also expand genetic counselling and promote screenings, allowing identification of asymptomatic heterozygotes;

$\rightarrow$ The recognition of at-risk subjects should lead to better planning of pregnancies and appropriate management of affected children at birth.

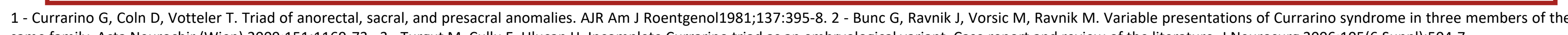
same family. Acta Neurochir (Wien) 2009;151:1169-73. 3 - Turgut M, Cullu E, Ulucan H. Incomplete Currarino triad as an embryological variant. Case report and review of the literature. J Neurosurg 2006;105(6 Suppl):504-7. 